\title{
Preoperative subcutaneous sildenafil injection increases random flap survival in rats ${ }^{1}$
}

\author{
Merdan Serin', Dincer Altinel', Cem Leblebici", Burcu Biltekin"', Mert Celikten ${ }^{\prime v}$, Fatih Irmak ${ }^{\vee}$, Sevgi \\ Kurt Yazar' \\ 'MD, Attending Physician, Istanbul Training and Research Hospital, Department of Plastic and Reconstructive Surgery, \\ Istanbul, Turkey. Scientific, intellectual, conception and design of the study; acquisition, analysis and interpretation of \\ data; technical procedures; statistical analysis; manuscript preparation and writing; critical revision. \\ "MD, Attending Physician, Istanbul Training and Research Hospital, Department of Pathology, Istanbul, Turkey. Technical \\ procedures. \\ '"Istanbul University, Cerrahpasa Medical School, Department of Histology and Embryology, Istanbul, Turkey. Technical \\ procedures. \\ IVIstanbul Bezmialem University Medical School, Animal Research Laboratory, Istanbul, Turkey. Technical procedures. \\ ${ }^{\vee} \mathrm{MD}$, Attending Physician, Sisli Etfal Training and Research Hospital, Department of Plastic and Reconstructive Surgery, \\ Istanbul, Turkey. Analysis and interpretation of data.
}

\begin{abstract}
Purpose: To investigate the effect of subcutaneous sildenafil on random flap survival.

Methods: Fourteen Wistar rats, which were divided in to two groups, were used for this experimental study. Rats in the sildenafil group received subcutaneous sildenafil injections daily for seven days before flap elevation. At the end of the treatment period, $9 \times 3 \mathrm{~cm}$ dorsal skin flaps were elevated and reinserted back into their place in all of the animals. Necrotic and whole flaps areas were recorded on graph papers. Seven days after the flap elevation samples for histological examination were taken and angiographies were performed to visualize the flap vascularization.
\end{abstract}

Results: The calculated average percentage of necrotic flap areas were $18.29 \%$ and $42.26 \%$ in the sildenafil and control group respectively. $(p=0.0233)$. In selected angiography images, vessels were found to be more prominent in the sildenafil group. The average number of capillary formations under light microscopy was higher in the sildenafil group ( $p=0.0286)$.

Conclusion: The subdermal high dose sildenafil has a positive effect on flap survival.

Key words: Sildenafil Citrate. Free Tissue Flaps. Rats. 


\section{- Introduction}

Random flaps are valuable tools in reconstructive surgery practice. Distal flap necrosis is commonly encountered in random flap surgery which can be caused by various anatomical or hemodynamic factors ${ }^{1}$. Various techniques and pharmacological agents have been studied to increase random flap survival ${ }^{2-4}$. Many of these studies have also been adapted to wound healing and tissue perfusion applications.

Sildenafil is a drug which inhibits Phosphodiesterase type 5 (PDE5) enzyme. This inhibition leads to an increase in the intracellular cGMP level which causes dilatation of blood vessels and relaxation of smooth muscles. PDE 5 inhibitors are approved for the treatment of pulmonary hypertension ${ }^{5}$ and erectile dysfunction ${ }^{6}$. Various side effects are associated with the systemic use of PDE5 inhibitors including low acute myocardial infarction ${ }^{7-9}$, headache, flushing, nasal congestion, hearing loss and optic neuropathy ${ }^{10}$.

Various studies have been made to investigate the effect of PDE5 inhibitors on flap survival ${ }^{11-16}$. These studies include oral and intraperitoneal administration of sildenafil. Considering the systemic side effects of sildenafil, in this study we examined the efficiency of subcutaneous sildenafil injection prior to surgery on random flap survival.

\section{- Methods}

The study was performed in the Bezmialem Vakif University Animal Research Laboratory with ethical comity approval.

Fourteen female 300-gram Wistar rats were used in the study. Surgical anesthesia was performed with Diethyl ether induction and intraperitoneal administration of $90 \mathrm{mg} /$ kg Ketamine (Pfizer ${ }^{\oplus}$, New York, USA) and 10 $\mathrm{mg} / \mathrm{kg}$ Xylazine (Bayer', Germany). An electric shaver was used to shave the back skin of animals. Povidone-iodine solution was used for skin preparation. Isoflurane (Adeka $\mathrm{Ilac}^{\circ}$, Turkey) was used for analgesia.

The animals were divided into two groups with seven animals in each:

Group 1 (Sildenafil group): $5 \mathrm{mg} / \mathrm{kg}$ of sildenafil in $5 \mathrm{ml}$ of saline solution was divided equally and injected from two points under the proposed flap areas for seven days daily before the flap elevation (Figure 1). Isoflurane inhalation anesthesia was used during the injection.

Group 2 (Control group): These animals were kept under the same conditions with the others without any pretreatment.

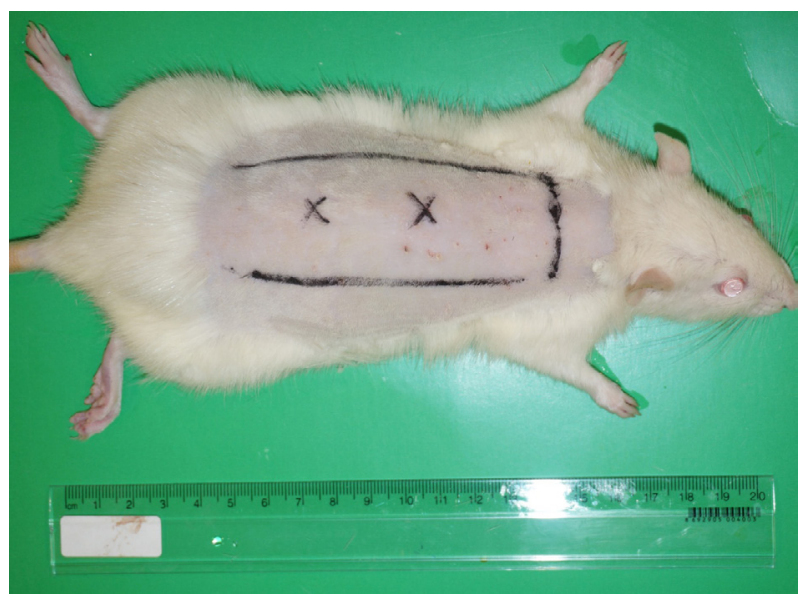

Figure 1 - Sildenafil injection points are marked under the proposed flap areas.

At the end of the first week caudally based dorsal skin flaps $9 \times 3 \mathrm{~cm}$ in size were raised and reinserted back into their place in all of the animals. The anatomical border of the flap was approximately from the scapula at the cephalic border to the posterior iliac crest at the caudal border (Figure 2). The flaps were sutured with polypropylene sutures. After the operation, daily photographs of the flaps were taken with a digital camera (Sony Nex-3N). The photographs at the postoperative seventh day were taken from a standard focus distance 
with milimetric graph papers and the necrotic/ whole flap areas were calculated using the VistaMetrix software (Version 1.35.0, Skillcrest LLC; USA) (Figure 3) ${ }^{17,18}$. Percentage of necrotic flap areas in each group were compared using Mann-Whitney test with Prism 7 software (La Jolla California USA).

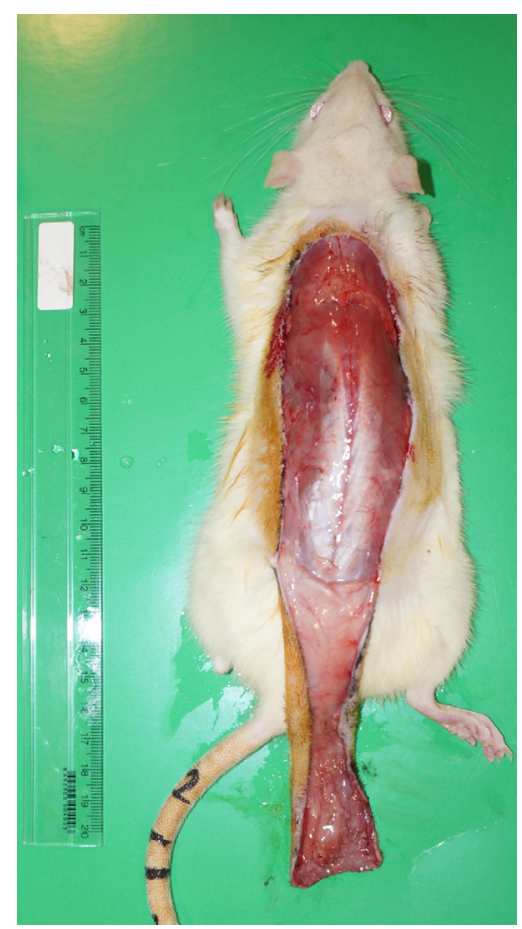

Figure 2 - Caudally based dorsal skin flap.

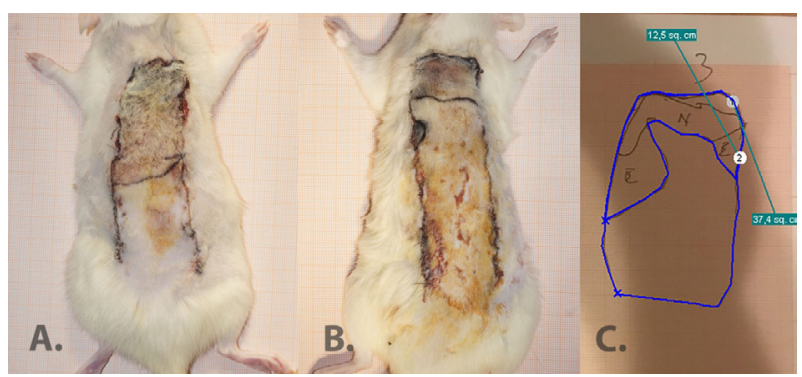

Figure $\mathbf{3}$ - Sample photographs of seventh-day flap areas. A. Control group; B. Sildenafil group; C. Calculation of necrotic and whole flap areas from graph papers.

Seven days after the flap elevation an incision on the abdominal wall was made to expose aorta and inferior vena cava for angiographic study. Abdominal aorta and inferior vena cava were cannulated with a 22-gauge and 20-gauge cannula respectively. High dose intravenous Pentothal Sodium (Abbott ${ }^{\circ}$, Turkey) was used to sacrifice the rats at this point when the collection of samples was performed from $3 \mathrm{~cm}$ distal to the base of the flaps for histological examination. $250 \mathrm{ml}$ of saline solution was administrated through aorta cannula to wash vascular bed $\% 40$ Barium sulfate (40 ml) (Yeni Ilac', Turkey) and $10 \mathrm{ml}$ of $\% 10$ gelatin were combined, heated and mixed in a solution of $100 \mathrm{ml}$ serum saline. The final solution was administrated into the circulation from the aorta. Both cannulas were then closed. The whole body of the animal was kept in $-18^{\circ} \mathrm{C}$ cooler overnight. The day following the operation the dorsal flap area was excised from the bodies of the animals. The flaps were stored in a refrigerator for another night at $+4 \stackrel{\circ}{ } \mathrm{C}$, and following day any remaining irrelevant tissues such as muscles and fascia were removed from the flap and fixed on a hard paper board. The flaps were taken into a mammography device for angiographic imaging (GE mammography machine $)^{19}$ (Figure 4).

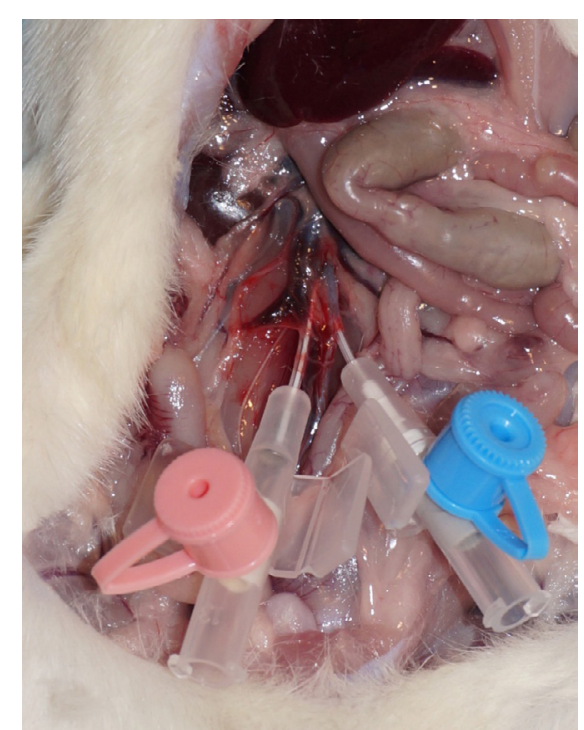

Figure 4 - Cannulation for angiography. 
The histological samples they were stained with hematoxylin and eosin. The samples were examined under light microscopy. The number of capillaries and inflammatory cells in the dermis were counted in samples from both groups in three different high-power fields by the same pathologist. The mean of three separate counts are calculated and statistical analysis was performed using Mann-Whitney test with Prism 7 software (La Jolla California USA).

\section{- Results}

\section{Flap area calculation results}

The calculated average percentages of necrotic flap areas were $18.29 \%$ and $42.26 \%$ in the sildenafil and control group respectively $(p=0.0233)$ (Figure 5).

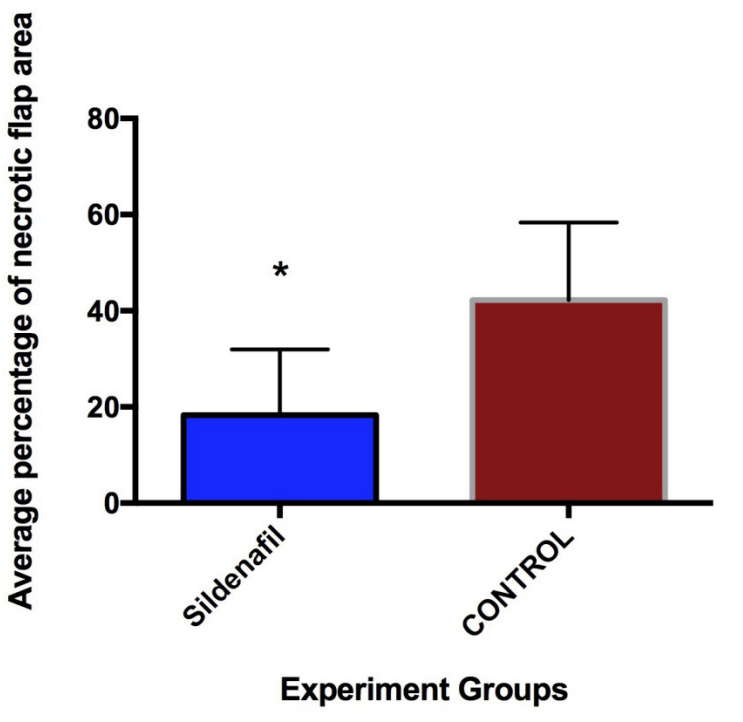

Figure 5 - Percentage of necrotic flap areas $\left({ }^{*} p<0.05\right)$.

\section{Evaluation of angiography images}

Flaps were fixed on hard paper boards to flatten the flap surface. The angiography images from the mammography device were analyzed on high magnification in the computer for the identification of vessel structures. Vessels formations were marked in all of the magnified images in each group. Statistical analysis was not performed but subjective evaluation of the selected images in the sildenafil group revealed more prominent vessel formations when compared with the control group (Figure 6).

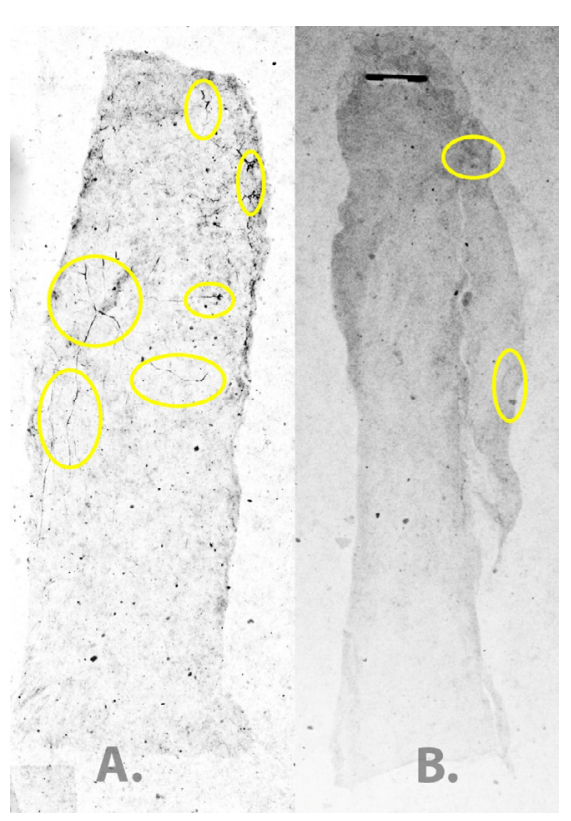

Figure 6 - Selected angiography images from each group (vessel formations are marked with circles). A. Sildenafil group. B. Control group.

\section{Evaluation of histological images}

The number of inflammatory cells were very low in both groups and differences among the groups were insignificant. The average number of capillary formations was were $6.75 \pm 0.95$ and $4.75 \pm 0.5$ in the sildenafil and control group respectively $(p=0.0286)$ (Figures 7 and 8). 


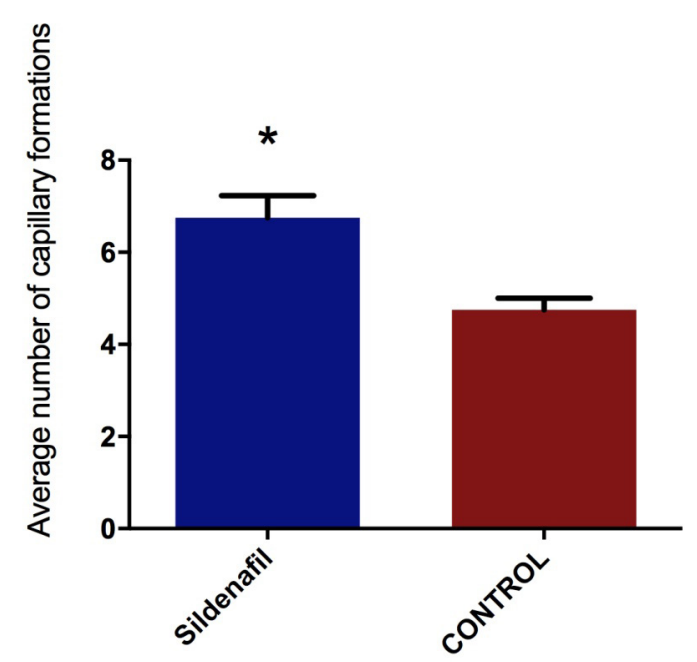

Figure 7 - Average number of capillary formations detected in histological analysis for each group $\left({ }^{*} p<0.05\right)$.

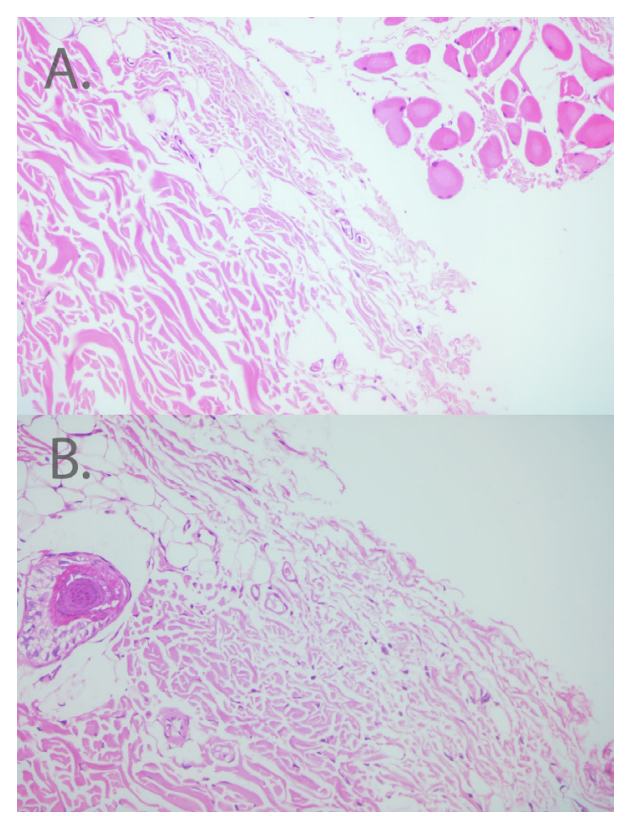

Figure 8 - Evaluation of histological images for capillary formations. A. Sildenafil group. B. Control group (H\&E, x200).

\section{- Discussion}

Various studies have been conducted to investigate the effects of PDE5 inhibitors on flap survival. Barral et al. ${ }^{20}$ and Ayyildiz et al. ${ }^{21}$ have investigated the effect of subdermal sildenafil injection on flap survival. These studies have a similar design to our study. But in these study sildenafil injection were administrated after the flap elevation. We believe that pretreatment of the flap will yield to more consistent and efficient results to increase the flap survival rate but further comparative studied would be required to prove this hypothesis. Ayyildiz et al. ${ }^{21}$ have investigated the effect of subdermal injection of $0.5 \mathrm{mg} / \mathrm{kg}$ sildenafil on flap survival. This study has showed the positive effects of subdermal sildenafil. We believe that the $6 \times 2$ $\mathrm{cm}$ flap dimension chosen in this study might have interfered with the results. Barral et al. ${ }^{20}$ has shown that $0.5 \mathrm{mg} / \mathrm{kg}$ can have a negative effect on flap survival which completely contradicts with the previous results. We have administrated much higher dosage of $5 \mathrm{mg} /$ $\mathrm{kg}$ sildenafil in this study when compared with previous studies in an attempt to augment the effects of this drug. Hart et al. ${ }^{11}$ has previously reported even higher dosage of intraperitoneal $9 \mathrm{mg} / \mathrm{kg}$ of sildenafil in a previous study.

In our study, the subdermal route of administration was preferred. We have hypothesized that this route would be more efficient to increase flap survival. In previous studies, other routes of sildenafil administration have resulted in confusing results on its effect on flap survival. Kaya et al. ${ }^{12}$ have shown that oral administration of sildenafil, tadalafil, and vardenafil have not led to a meaningful increase in the flap survival rate. Sarifakioglu et al. ${ }^{14}$ have also reported a similar result with oral sildenafil. On the other hand, Hart et al. ${ }^{11}$ have found that intraperitoneal injection of sildenafil could have a positive increase in flap survival on the early postoperative period.

Serious side effects including hypotension, myocardial infarcts, and optic neuropathies have been reported with use of systemic PDE5 inhibitors. In this study, we believe that the use of subdermal injection method compared to other administration methods can reduce the risk of adverse effects 
reported with PDE5 inhibitor. This approach can allow the administration of higher doses of sildenafil with minimal systemic effects.

In this current study, we have found a considerable increase in flap survival with subdermal sildenafil. Although the angiography results supported these findings, it should be noted that angiography evaluation was subjective and obtaining clear images was highly demanding. To overcome this shortcoming further histological analysis was performed. The results from histological evaluation revealed increased number of capillary formations in the sildenafil group under light microscopy. These findings does further the support flap survival and angiography results.

In this study we preferred the use of a control group without any pretreatment instead of a sham group with saline injection. We hypothesized that the effect of the trauma of the injection could have caused a different amount of increase in the amount of necrosis in each animal in the control group which could been harder to evaluate. The other reason being was to obtain better angiography images in the control groups.

\section{Conclusions}

The subdermal sildenafil prior to surgery has a positive increase in flap survival. The underlying mechanism under this finding has to be further investigated. Studies involving Doppler investigation rather than angiographies might give better insight to the change in the blood flow. Other effects of a decrease in the cGMP concentrations such alterations in ion channels might have other impacts on microcirculation and flap survival.

\section{References}

1. Matsumura $\mathrm{H}$, Yoshizawa N, Vedder NB, Watanabe K. Preconditioning of the distal portion of a rat random-pattern skin flap.
Br J Plast Surg. 2001 Jan;54(1):58-61. PMID: 11121320.

2. Basu G, Downey H, Guo S, Israel A, Asmar A, Hargrave B, Heller R. Prevention of distal flap necrosis in a rat random skin flap model by gene electro transfer delivering VEGF(165) plasmid. J Gene Med. 2014 MarApr;16(3-4):55-65. PMID: 25551865.

3. Park SW, Oh TS, Choi JW, Koh KS. Preconditioning by pressure controlled cupping enhances survival of random flap in rat model. Plast Reconstr Surg. 2015 Oct;136(4 Suppl):34. PMID: 26397526.

4. Seyed Jafari SM, Shafighi M, Beltraminelli $H$, GeiserT, Hunger RE, Gazdhar A. Improvement of flap necrosis in a rat random skin flap model by in vivo electroporation-mediated HGF gene transfer. Plast Reconstr Surg. 2017 May;139(5):1116e-27e. PMID: 28445365.

5. Hemnes AR, Champion HC. Sildenafil, a PDE5 inhibitor, in the treatment of pulmonary hypertension. Expert Rev Cardiovasc Ther. 2006 May;4(3):293-300. PMID: 16716091.

6. Noss MB, Christ GJ, Melman A. Sildenafil: a new oral therapy for erectile dysfunction. Drugs Today (Barc). 1999 Mar;35(3):211-7. PMID: 12973386.

7. Ishikura F, Beppu S, Hamada T, Khandheria BK, Seward JB, Nehra A. Effects of sildenafil citrate (Viagra) combined with nitrate on the heart. Circulation. 2000 Nov 14;102(20):2516-21. PMID: 11076826.

8. Porter A, Mager A, Birnbaum Y, Strasberg B, Sclarovsky S, Rechavia E. Acute myocardial infarction following sildenafil citrate (Viagra) intake in a nitrate-free patient. Clin Cardiol. 1999 Nov;22(11):762-3. PMID: 10554698.

9. Webb DJ, Freestone S, Allen MJ, Muirhead GJ. Sildenafil citrate and blood-pressurelowering drugs: results of drug interaction studies with an organic nitrate and a calcium antagonist. Am J Cardiol. 1999 Mar 04;83(5A):21C-8C. PMID: 10078539.

10. Foresta C, Caretta N, Zuccarello D, Poletti A, Biagioli A, Caretti L, Galan A. Expression of the PDE5 enzyme on human retinal tissue: new aspects of PDE5 inhibitors ocular side effects. Eye (Lond). 2008 Jan;22(1):144-9. PMID: 17585311.

11. Hart K, Baur D, Hodam J, Lesoon-Wood L, Parham M, Keith K, Vazquez R, Ager E, Pizarro J. Short- and long-term effects of sildenafil on skin flap survival in rats. Laryngoscope. 
2006 Apr;116(4):522-8. PMID: 16585853.

12. Kaya B, Cerkez C, Isilgan SE, GokturkH, Yigman $Z$, Serel S, Can B, Ergun H. Comparison of the effects of systemic sildenafil, tadalafil, and vardenafil treatments on skin flap survival in rats. J Plast Surg Hand Surg. 2015;49(6):35862. PMID: 26107909.

13. Kelahmetoglu O, Demir R, Okten G, Demir A, Alpaslan Pinarli F, Diraman E. The effect of mesenchymal stem cells and sildenafil on flap viability in perforator-based flaps for ischemia/reperfusion injury: An experimental study. Microsurgery. 2015 Feb 27. PMID: 25726839.

14.Sarifakioglu N, Gokrem S, Ates L, Akbuga UB, Aslan G. The influence of sildenafil on random skin flap survival in rats: an experimental study. Br J Plast Surg. 2004 Dec;57(8):769-72. PMID: 15544775.

15.Tsai JW, Ayubi FS, Hart KL, Baur DA, Parham MA, Moon JK, Vazquez R, Chasen AB, Zhang $Z$, Pizarro JM. Evaluation of the effect of sildenafil and vascular endothelium growth factor combination treatment on skin flap survival in rats. Aesthetic Plast Surg. 2008 Jul;32(4):624-31. PMID: 18443849.

16.Ulusoy MG, Uysal A, Kocer U, Karaaslan O, Cuzdan SS, Ayyildiz A, Ustun H. Improved flap viability with site-specific delivery of sildenafil citrate using fibrin glue. Ann Plast Surg. 2005 Sep;55(3):292-6. PMID: 16106170.

17. Hurn IL, Fisher JC, Arganese T, Rudolph R. Standardization of the dorsal rat flap model. Ann Plast Surg. 1983 Sep;11(3):210-3. PMID: 6638820.

18. Hammond DC, Brooksher RD, Mann RJ, Beernink JH. The dorsal skin-flap model in the rat: factors influencing survival. Plast Reconstr Surg. 1993 Feb;91(2):316-21. PMID: 8430147.

19.Quinodoz P, Quinodoz M, Nussbaum JL, Montandon D, Pittet B. Barium sulphate and soft-tissue radiology: allying the old and the new for the investigation of animal cutaneous microcirculation. Br J Plast Surg. 2002 Dec;55(8):664-7. PMID: 12550120.

20.Barral SM, Araujo ID, Vidigal PV, Mayrink CA, Araujo AD, Costa PR. Effects of sildenafil on the viability of random skin flaps. Acta Cir Bras. 2011 Aug;26(4):314-9. PMID: 21808846.

21.Ayyildiz A, Uysal A, Kocer U, Karaaslan O, Huri E, Germiyanoglu C, Caydere M. Effect of sildenafil citrate on viability of flaps: an experimental study in rats. Scand J Plast Reconstr Surg Hand Surg. 2005;39(4):204-8. PMID: 16208781.

\section{Correspondence:}

Merdan Serin

Istanbul Research and Teaching Hospital

Department of Plastic Surgery

Istanbul Turkey

merdanserin@gmail.com

Received: Nov 16, 2017

Review: Jan 18, 2018

Accepted: Feb 20, 2018
Conflict of interest: none

Financial source: none

\begin{abstract}
${ }^{1}$ Research performed at Animal Research Laboratory, Faculty of Medicine, Istanbul Bezmialem University, Istanbul, Turkey.
\end{abstract}

